\title{
Charge Transfer Resistance and Adsorption performance of a New Pyrrole derivative on Mild steel in Acidic media: Antibacterial studies
}

\author{
G. PANDIMUTHU1,2, P. MUTHUKRISHNAN ${ }^{3}$, S. RAMESHKUMAR ${ }^{4}$, \\ K. PARAMASIVAGANESH ${ }^{2}$ and A. SANKAR ${ }^{1 *}$
}

\begin{abstract}
'Department of Chemistry, Kandaswami Kandar's College, P. Velur, Namakkal-638 182, India. ${ }^{2}$ Department of Chemistry, Arumugam Pillai Seethai Ammal College,Tiruppatur-630211, India. ${ }^{3}$ Department of Chemistry, Faculty of Engineering, Karpagam Academy of Higher Education, Coimbatore-641021, India.

${ }^{4}$ Department of Chemistry, Sri Vasavi College, Erode-638316, India.

${ }^{*}$ Corresponding author E-mail: sanvishnu2010@gmail.com
\end{abstract}

http://dx.doi.org/10.13005/ojc/370403

(Received: April 30, 2021; Accepted: July 11, 2021)

\begin{abstract}
In the present work, Pyrrole derivatives containing oxygen, nitrogen and aromatic rings namely, $\mathrm{N}$-(1H-Pyrrol-2-ylmethylidene)-2,3-dihydro-1,4-benzodioxin-6-amine (BPS) was synthesized and its anticorrosion potential was studied applying the gravimetric, polarization and AC impedance methods on the mild steel (MS) corrosion in corrodent $\left(0.5 \mathrm{M} \mathrm{H}_{2} \mathrm{SO}_{4}\right.$ and $\left.1 \mathrm{M} \mathrm{HCl}\right)$. It is observed that in the acidic environments, the inhibition efficiency (IE) of the BPS raised with the enhance in the concentration and it resulted in greater inhibition efficiency in $1 \mathrm{M} \mathrm{HCl}$ solution than in $0.5 \mathrm{M} \mathrm{H}_{2} \mathrm{SO}_{4}$ solution. The inhibition efficiency assessed by Electrochemical Impedance Spectroscopy reaches about $81.6 \%$ in $0.5 \mathrm{M} \mathrm{H}_{2} \mathrm{SO}_{4}$ and $84.2 \%$ in $1.0 \mathrm{M} \mathrm{HCl}$ solutions at $600 \mathrm{ppm}$ of BPS. The studied BPS being mixed type inhibitor was shown by the Tafel polarization curves. And it was noticed that over the MS surface, the adsorption of the BPS obeyed Langmuir isotherm. In order to ascertain the inhibitor mechanism, the potential of zero charge (PZC) was measured. Electrochemical Impedance spectroscopy was applied to assess the influence of temperature on corrosion inhibition. The surface morphology of MS surface was analyzed using SEM and AFM techniques. The anti-bacterial activity for the BPS was studied as a divergent analysis.
\end{abstract}

Keywords: Schiff base, Corrosion inhibition, Electrochemical impedance spectroscopy, Adsorption isotherm, PZC, Anti-bacterial activity.

\section{INTRODUCTION}

The thermodynamic instability of metals and alloys is major reason for their corrosion in the given environment. Alloy is prominently employed as fencing, instrumental and industrial materials and in acidic medium, it is vulnerable to corrosion'. To control the corrosion of metals and alloys in many corrosion environments inhibitors can be used ${ }^{2}$. The application of organic inhibitors is known as one

This is an Open Access article licensed under a Creative Commons license: Attribution 4.0 International (CC- BY). Published by Oriental Scientific Publishing Company @ 2018

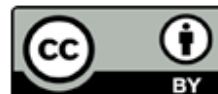


of the most important processes in the aspect of prevention of corrosion and controlling it $\mathrm{it}^{3,4}$. The vital ingredient in the mechanistic side of the inhibitors is the specific interaction of such inhibitor's functional groups or atoms with the corrosion active centers on the metal surface ${ }^{5}$. In this interaction, the organic compounds that contain the heteroatoms like N,O,S etc have important roles to play with the donation of the free lone pair of electrons to the orbitals of metal atoms that are vacant in the active centres ${ }^{6-16}$. Moreover, the compounds with $\pi$ bonds also exhibit good corrosion inhibiting properties due to interaction between the surface of the metals and pi-electrons. Schiff bases are organic compounds that meet practically all of the requirements of an effective inhibitor and have azomethine linkage having a pair of valence electrons on nitrogen atom and pi-electrons act as potential corrosion inhibitors ${ }^{8-11}$. Due to the availability of various possible structures with respect to the aldehyde and amine used the Schiff base field has developed at a faster pace. As the industrial and biological applications of many Schiff bases and their complexes are worthy, they are widely studied ${ }^{12}$. These molecules have the potential to create a monolayer spontaneously over the surface of metals and alloys to be protected in the corrosive media ${ }^{13}$ and found to possess higher inhibition efficiency than their constituent amines and carbonyls $\mathbf{s}^{14,15}$.

Economic consideration and electron cloud on the benzene structure or $\mathrm{N}, \mathrm{O}$ atoms in the comparatively long chain compound are the two choices available to choose the inhibitor ${ }^{16}$. The present work describes the synthesize of a Schiff base, BPS and to compare its corrosion inhibitive properties for the corrosion of MS in $\mathrm{HC} 1(1 \mathrm{M})$ and $0.5 \mathrm{M} \mathrm{H}_{2} \mathrm{SO}_{4}$ acid by electrochemical studies. The antibacterial activity of this compound is also explained from the experimental results.

\section{EXPERIMENTAL}

Mild steel specimens, cut from a mild steel plate, with dimensions $2.5 \mathrm{~cm}, 1.0 \mathrm{~cm}$ and $0.1 \mathrm{~cm}$ have been used for weight loss studies. To carry out electrochemical studies a mild steel rod in cylindrical shape coated with araldite with an uncovered area of $0.2826 \mathrm{~cm}^{2}$ was employed where the required composition of mild steel specimens was maintained as $0.032 \% \mathrm{Mn}, 0.029 \% \mathrm{~S}, 0.092 \% \mathrm{C}$ and $\mathrm{Fe}$ as the remaining. Mechanical polishing of the rods using emery sheets (120 to 1200 grade) was performed and then it was completely washed using deionized water. After that degreasing using acetone was performed before it was dried. Using double distilled water, corrodents $\left(1 \mathrm{M} \mathrm{HCl}\right.$ and $0.5 \mathrm{M} \mathrm{H}_{2} \mathrm{SO}_{4}$ ) were prepared from the AR grade reagents. In order to maintain the solubility reasons of the inhibitor, a volume of $3 \%$ ethanol was added to the acid solutions.

\section{Synthesis of Schiff base}

The precursors 1,4-Benodioxan-6-amine and Pyrrole-2-carboxaldehyde were dissolved in minimum amount of ethanol separately in 1:1 mole ratio and then these solutions were mixed in a round bottom flask fitted with an air condenser. The mixture is refluxed at $45^{\circ} \mathrm{C}$ for six hours and finally poured in ice cold water, a white colored compound separated out. This solid is recrystallized using ethanol and used as corrosion inhibitor. The reaction scheme is shown in Fig. 1. The synthesized BPS was confirmed by the appearance of new peak for $>\mathrm{C}=\mathrm{N}$-in the Schiff base at $1726 \mathrm{~cm}^{-1}$ and disappearance of characteristics peaks for the functional groups of the starting materials. The FTIR spectra (spectrum) of the synthesized Schiff base (BPS) is shown in Figure 2.

\section{Non-Electrochemical measurements}

Measurements to assess the mass loss were recorded adhereing to the standard methodology codified by ASTM for Testing and Materials ${ }^{17}$. Maintaining the room temperature at $\left(30 \pm 1^{\circ} \mathrm{C}\right)$, three sets of tested MS were kept dipped in both the inhibited and uninhibited medium of 100 $\mathrm{mL}$ quantity for about two hours. The specimens were taken out of the test solution after $2 \mathrm{~h}$, washed in deionized water, dried thoroughly and weighed. The method was repeated three times to ensure that the mass loss data consistent. The formula was applied to determine the inhibition efficiency based on the weight of the specimens as measured in the tested solutions.

$\mathrm{IE} \%=\left(\frac{\mathrm{W}-\mathrm{W}^{\prime}}{\mathrm{W}}\right) \mathrm{X} 100$

Here w denotes the mass loss of the MS 
in the tested corrodents and w' denotes the mass loss of the MS in the presence of BPS. The average weight of triplicate specimens has been employed for the gravimetric studies.

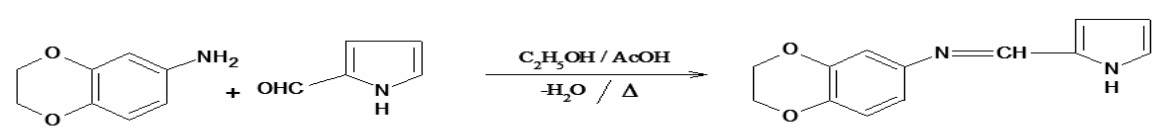

1,4-Benzodioxin-6-amine Pyrrole-2-carbaldehyde N-(1H-Pyrrol-2-ylmethylidene)-2,3-dihydro-1,4-benzodioxin-6-amine (BPS)

Fig. 1. Scheme for BPS formation

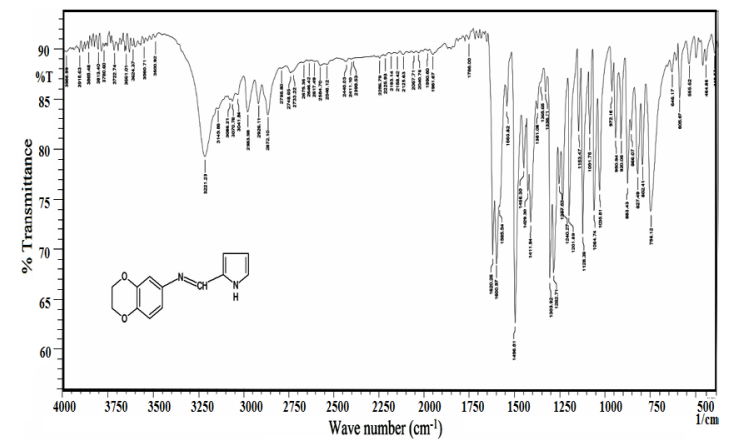

Fig. 2. FT-IR Spectra (spectrum) of BPS

Electrochemical Impedance Spectroscopic (EIS) Measurements

The electrochemical impedance was recorded in the presence and absence of BPS in tested corrodents, with reference to the corrosion of mild steel in corrodents with the application of PARSTAT 2273 Potentiostat/Galvanostat. The inbuild software Power Suite was employed to derive the electrochemical impedance parameters and Zsimpwin Software (version 3.21) was applied for analysis. A three electrode structure in the acid media was used to record the impedance spectra, In this process, a Pt foil did the work of auxiliary electrode, whereas a saturated calomel electrode served as a reference. In the same way, a teflon coated mild steel rod of the same composition played the role of working electrode. In order to achieve a steady value for corrosion potential, the rod coated with Teflon was sinked for about thirty minutes in the corrodents, before the EIS spectra was recorded. When the AC frequency range was $100000 \mathrm{~Hz}$ to $0.01 \mathrm{~Hz}$, the recording of impedance spectra was completed with the AC signal amplitude of $10 \mathrm{mV}$ being at the corrosion potential. The charge transfer resistance $\left(R_{c t}\right)$ and double layer capacitance $\left(C_{d l}\right)$ were secured from the Impedance curves as noted ${ }^{18}$. The $\mathrm{R}_{\mathrm{ct}}$ and $\mathrm{C}_{\mathrm{dl}}$ values calculated as

$R_{c t}=\left(R_{s}+R_{c t}\right)-R_{s}$

$C_{d l}=1 / 2 \pi \times f_{\max } \times R_{c t}$
Here $R_{s}$ denotes the solution resistance and $f_{\max }$ denotes the maximum frequency. The calculation of inhibition efficiency was carried out with the application of the formula as the value of $R_{c t}$ was found to be inversely proportional to corrosion rate.

$\mathrm{IE} \%=100 \times \frac{\left(\mathrm{R}_{\mathrm{Ct}}^{\prime}-\mathrm{R}_{\mathrm{ct}}\right)}{\mathrm{R}_{\mathrm{ct}}}$

The EIS spectra were measured at a fixed single frequency $(200 \mathrm{~Hz})$ for the inhibited and uninhibited acid solutions by superimposing the input $\mathrm{AC}$ sinusoidal voltage of small amplitude $10 \mathrm{mV}$ at different DC potentials. To calculate the PZC, a graph was plotted applied DC potential against $\mathrm{C}_{\mathrm{dl}}$.

\section{Polarization Measurements}

Employing the kind of setup already used, the Tafel polarization studies for the measurements of impedance spectra were carried out. Keeping the rate of scan at $1.66 \mathrm{mV} / \mathrm{sec}$, the potentials were swept. This process was carried out initially from a potential that is more negative to more positive. The corrosion potential $\left(\mathrm{E}_{\text {corr }}\right)$, the density of corrosion current $\left(\mathrm{i}_{\text {corr }}\right)$ and Tafel constants $(\beta \mathrm{a}$ and $\beta \mathrm{c}$ ) were secured from the plot of electrode potential vs logi at various concentrations of inhibitor. In the formula, Icorr represents the current density of the corrosion in the absence of the tested compounds and I' refers to the current density of the corrosion in the presence of the tested compounds.

$$
\mathrm{IE} \%=\frac{\left(\mathrm{i}_{\text {corr }}-\mathrm{i}_{\text {corr }}\right)}{\mathrm{i}_{\text {corr }}} \times 100
$$

\section{Temperature Effect}

The influence of temperature on the mild steel corrosion in corrosive media and corrosion inhibition performance of synthesized Schiff base was studied in the temperature range $303-323 \mathrm{~K}$ using electrochemical impedance spectroscopy.
Analysis of Surface Morphology
SEM (Model JEOL-JSM-6390) was used to examine the surface conditions of mild steel. The morphology of the tested specimens immersed in 
the presence of BPS and presence of BPS were analyzed at the magnification of $2.0 \mathrm{KX}$.

\section{Assessment of Surface Roughness}

The surface of MS soaked in the inhibited and uninhibited acid solutions was also analyzed using Atomic force microscope (Veecodilnnova model). The area of MS was $5 \mu \mathrm{m} \times 5 \mu \mathrm{m}$ at a scan rate of $0.6 \mathrm{~Hz}$.

\section{Anti-Microbial Studies}

The fungi A.Niger and C.Albicans and the Staphylococcus aureus (Gram-positive bacteria) and Bacillus the Gram-negative bacteria Salmonella typhi and $E$. coli were used to test the In-vitro antifungal and antibacterial activities of the synthesized BPS. In order to conduct antibiotic sensitivity test, the Kirby-Bauer disc diffusion method is generally applied (Kirby-Bauer et al., 1966). Having prepared the Muller Hinton agar it was sterilized and poured onto sterile petriplates. An approximate depth of $4 \mathrm{~mm}$ was maintained for the medium. To remove the excess moisture from the surface, the plates were dried for about $30 \mathrm{~min}$ in an incubator, after solidification. Selecting a single colony from the quadrant streak plate, it was inoculated into sterile nutrient broth and maintaining the temperature at $35-37^{\circ} \mathrm{C}$ for about $2-5 \mathrm{~h}$ the was well incubated. As the next step, adhereing to the McFarland standard, the size of the inoculums was also standardized.

\section{RESULTS AND DISCUSSION}

\section{Effect of BPS}

Figure 3 displays the $C R$ and IE\% calculated from the mass loss analysis. It is inferred from this figure that the CR of MS decreases and inhibition efficiency increases upon the addition of BPS from 50ppm to 600ppm in both the acid media. The increase in corrosion inhibition efficiency with the concentration of inhibitor in the acid media well deciphered the adsorption of BPS on the MS surface and thus, the surface area of mild steel specimens in contact with the corrosive media decreases. We observed the highest corrosion inhibition efficiency ( $84.5 \%$ in $1.0 \mathrm{M} \mathrm{HCl}$ and $82.2 \%$ in $0.5 \mathrm{M} \mathrm{H}_{2} \mathrm{SO}_{4}$ ) at $600 \mathrm{ppm}$ of BPS. Corrosion inhibition does not rise significantly above this concentration. The experimental results clearly indicated that the corrosion inhibition efficiency of BPS in $1.0 \mathrm{M} \mathrm{HCl}$ is greater than in $0.5 \mathrm{M} \mathrm{H}_{2} \mathrm{SO}_{4}$ solution. This is due to the fact that in acid solutions the MS surface is positively charged and the $\mathrm{Cl}^{-}$ions get adsorbed on the MS surface through physisorption. The $\mathrm{Cl}^{-}$ions adsorbed onto the MS surface connected with the positively charged protonated Schiff base molecules which increase the surface coverage of inhibitor molecules. This effect is less in the case of sulphate ions sulphuric acid solution.

\section{Electrochemical Impedance Spectroscopy (EIS)} Electrochemical Impedance Spectroscopy is used to test the inhibition efficiency of the synthesized BPS on MS corrosion in aqueous corrodents. The impedance spectra for MS rod corrosion in both the corrodents in the absence and presence of BPS at different concentrations are depicted in Figure $4 a \& 4 b$.

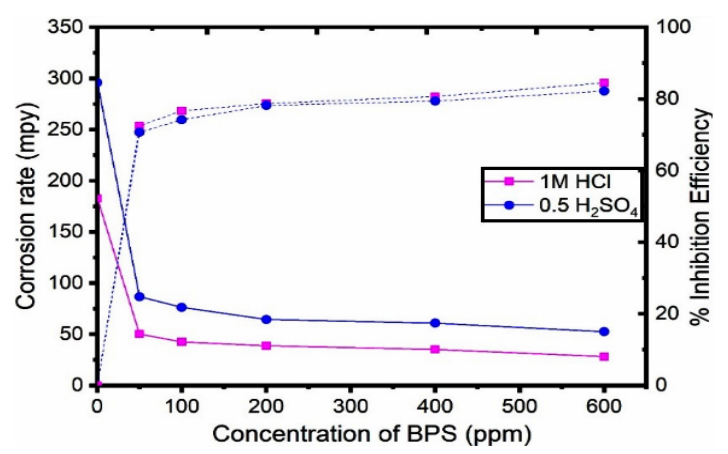

Fig. 3. Effect of BPS on CR (-) and \% IE (---) in tested corrodents for mild steel
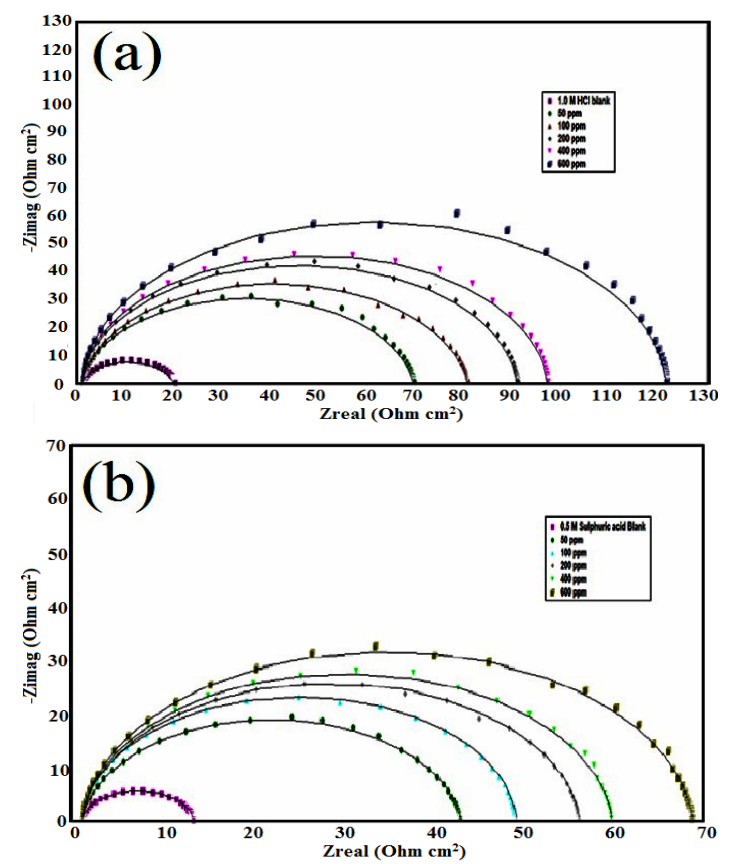

Fig. 4. Effect of BPS on the Nyquist curves in (a) ${ }^{1} \mathrm{M} \mathrm{HCl}$ and (b) $0.5 \mathrm{M} \mathrm{H}_{2} \mathrm{SO}_{4}$ solutions 
Generally, the EIS plots obtained are not straight forward; we can't get the values of impedance parameters from the plots directly. To extract the electrochemical impedance parameters from the plots the equivalent circuits are used. The equivalent circuit which fits well with the experimental curves is found and used to extract the impedance parameters. In the present case, the investigated data well fitted with the equivalent circuit depicted in Fig. 5. This equivalent circuit is called simple Randle's circuit and represented as-R (CR)-model. From Fig. 4a and 4b, it is obvious that the experimental impedance curves are semi circles with depressed nature. This can be attributed to the nonideal capacity behavior of electrode-corrosive media interface ${ }^{20-23}$. According to these results, chemical in homogeneities, surface roughness, anion adsorption and the degree of poly crystallinity cause dispersion of $\mathrm{Cdl}$ at the electrolyte-electrode interface ${ }^{20,22}$. A definite model for this phenomenon is expressed by replacing the capacitor with a constant phase element $(\mathrm{CPE})^{20,22}$ and the equivalent circuit is displayed in Figure 4.

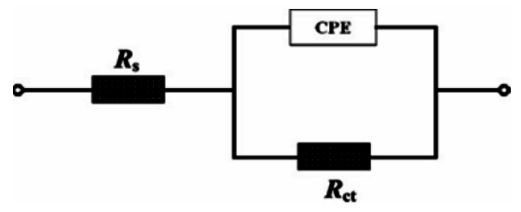

Fig. 5. Equivalent circuit of the EIS
Table 1 displays the Impedance parameters obtained by fitting the equivalent circuit with the experimental Nyquist curves for MS corrosion in both the acid media in the absence and presence of BPS. Table 1 clearly shows that as the concentration of BPS rises, the $R_{c t}$ increases while the $C_{d l}$ decreases. This is owing to efficient adsorption of the BPS molecules on the MS surface. The $C_{d 1}$ values were calculated using the admittance $\left(\mathrm{Y}_{0}\right)$ and CPE parameter (n) as follows ${ }^{24}$,

$C_{d l}=Y_{0} \omega n^{-1}$

Where $\omega$ is the angular frequency. As presented in Table 1, the comparison of the $R_{c t}$ values of blank with BPS system is indicative of the result that the presence of BPS goes on to increase coverage degree $(\theta)$. This is attributed to increased efficiency of inhibition ${ }^{25-27}$. This is due to BPS adsorption at the electrode-electrolyte interface which caused the adsorbed water molecules to be replaced, resulting an increase in the electrical double layer thickness and/or drop in local dielectric constant ${ }^{28}$. As a result, the reduction in $\mathrm{C}_{\mathrm{dl}}$ values caused by BPS adsorption on the mild steel surface reduces the extent of the corrosion ${ }^{29-31}$.

Table 1.Electrochemical impedance parameters for effect of BPS on MS in tested corrodents

\begin{tabular}{lccccc}
\hline Medium & $\begin{array}{c}\text { Concentration of the } \\
\text { Schiff base }(\mathrm{ppm})\end{array}$ & $\mathrm{R}_{\mathrm{ct}}(\mathrm{Ohm} \mathrm{cm})$ & $\mathrm{N}$ & $\left.\mathrm{C}_{\mathrm{dl}}(\mu \mathrm{F} \mathrm{cm})^{-2}\right)$ & $\begin{array}{c}\text { Inhibition } \\
\text { Efficiency }(\%)\end{array}$ \\
\hline & 0 & 19.1 & 0.912 & 173 & - \\
Coverage $(\theta)$
\end{tabular}

\section{Polarization Measurements}

Figure $6 \mathrm{a}$ and $6 \mathrm{~b}$ display Tafel plots for MS corrosion in tested corrodents. As seen in Fig. 6 , when BPS is added to acid solutions, the corrosion current decreases in both cathodic and anodic areas. The potentiodynamic polarization parameters are presented in Table 2. As shown in this table and Tafel plots, the corrosion current density decreases as the concentration of BPS increases. It seems from Fig. 6 that the $E_{\text {corr }}$ is shifted both in the anodic and cathodic directions with the addition of inhibitor to acid solutions. However, the shift is not greater than $78 \mathrm{mV}$ on either directions. This also confirms the mixed type inhibition. Moreover, the values of $\beta a$ and $\beta c$ change with the concentration of BPS. From this observation it is believed that BPS molecules adsorbed on mild steel surface control corrosion in both the areas of working electrode surface. 

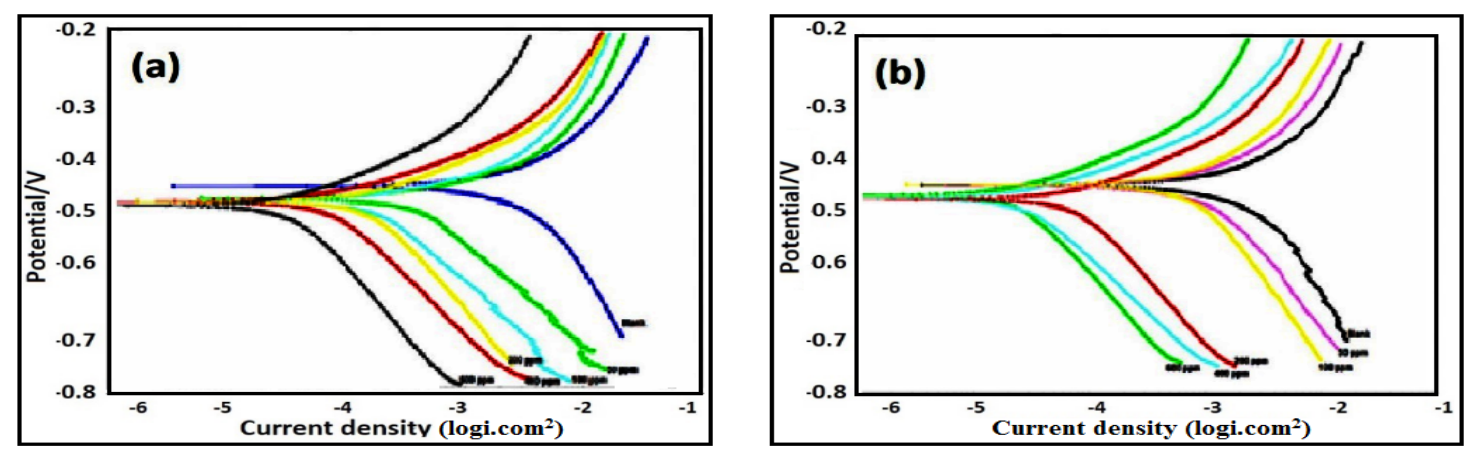

Fig. 6. The change of potential with current density at different concentrations of BPS

Table 2: Tafel polarization parameters for adsorption of BPS on MS in both corrodent

\begin{tabular}{|c|c|c|c|c|c|c|c|}
\hline Corrodents & $\begin{array}{c}\text { Conc.of the } \\
\text { Schiff base (ppm) }\end{array}$ & $\mathrm{E}_{\text {corr }}(\mathrm{mV})$ & $\mathrm{I}_{\text {corr }}\left(\mathrm{mA} \mathrm{cm} \mathrm{cm}^{-2}\right)$ & $\beta a$ & $\beta c$ & $\begin{array}{c}\text { Inhibition } \\
\text { Efficiency (\%) }\end{array}$ & $\begin{array}{c}\text { Surface } \\
\text { Coverage }(\theta)\end{array}$ \\
\hline & 0 & -450 & 1.17 & 110 & 257 & - & - \\
\hline & 50 & -474 & 0.333 & 98 & 219 & 71.5 & 0.715 \\
\hline & 100 & -485 & 0.289 & 108 & 222 & 75.3 & 0.753 \\
\hline \multirow[t]{6}{*}{$\mathrm{HCl}(1 \mathrm{M})$} & 200 & -487 & 0.256 & 112 & 213 & 78.1 & 0.781 \\
\hline & 400 & -491 & 0.237 & 114 & 227 & 79.7 & 0.797 \\
\hline & 600 & -496 & 0.193 & 103 & 231 & 83.5 & 0.835 \\
\hline & 0 & -448 & 2.93 & 143.9 & 245 & - & - \\
\hline & 50 & -449 & 0.876 & 89 & 128 & 70.1 & 0.701 \\
\hline & 100 & -442 & 0.771 & 92 & 119 & 73.7 & 0.737 \\
\hline \multirow[t]{3}{*}{$\mathrm{H}_{2} \mathrm{SO}_{4}(0.5 \mathrm{M})$} & 200 & -476 & 0.668 & 98 & 116 & 77.2 & 0.772 \\
\hline & 400 & -471 & 0.63 & 89 & 127 & 78.5 & 0.785 \\
\hline & 600 & -467 & 0.551 & 87 & 129 & 81.2 & 0.812 \\
\hline
\end{tabular}

Determination of Potential of Zero Charge (PZC)

The obtained $E_{O C P}$ and $E_{P Z C}$ values obtained from the potential of zero charge study for electrode in the presence and absence of BPS in the two acid media are displayed in Table 3. At the open circuit potential, the charge of the MS surface in the corrosive media is determined utilizing the equation;

$E_{r}=E_{O C P}-E_{P Z C}$

Open circuit potential values were found to be positive in the corrodents with or without BPS with respect to PZC. In uninhibited acid solutions the anions from the acid get attached on the positive sites of the metal. The Schiff base molecules can exist in protonated from via protonation of lone pair electrons on the nitrogen atom in acid media through a complex equilibrium. The protonated Schiff base molecules can't get attached to the positively charged metal surface in acid media in the inhibited acid media. However, the anions from acid can get attached to the metal surface and will help to attach the positively charged Schiff base molecules from the solution i.e. the anions act as bridge. The non-protonated molecules tend to occupy the vacant adsorption sites (not covered by anions) on the working electrode surface. In this situation, the $\mathrm{Cl}^{-}$and $\mathrm{SO}_{4}{ }^{2-}$ ions adsorbed on the electrode surface and increases the negative charge on the surface which is decreased by the adsorption of protonated BPS molecules through electrostatic attraction ${ }^{32}$. The corrosion inhibition mechanism could be explained by following Figures 7 and 8 .

Table 3: PZC corresponding to different tested medium obtained with EIS test

\begin{tabular}{lcccc}
\hline S.No. & Medium & Eocp $(\mathrm{mV})$ & PZC $(\mathrm{mV})$ & Excess Charge \\
\hline 1 & $1.0 \mathrm{M} \mathrm{HCl}$ & -450 & -520 & + \\
2 & $1.0 \mathrm{M} \mathrm{HCl}$ & -466 & -540 & + \\
& $+600 \mathrm{ppm} \mathrm{of} \mathrm{inhibitor}$ & & & \\
3 & $0.5 \mathrm{M} \mathrm{H}_{2} \mathrm{SO}_{4}$ & -455 & -480 & + \\
4 & $0.5 \mathrm{M} \mathrm{H}_{2} \mathrm{SO}_{4}+600 \mathrm{ppm}^{2}$ of inhibitor & -450 & -540 & + \\
\hline
\end{tabular}




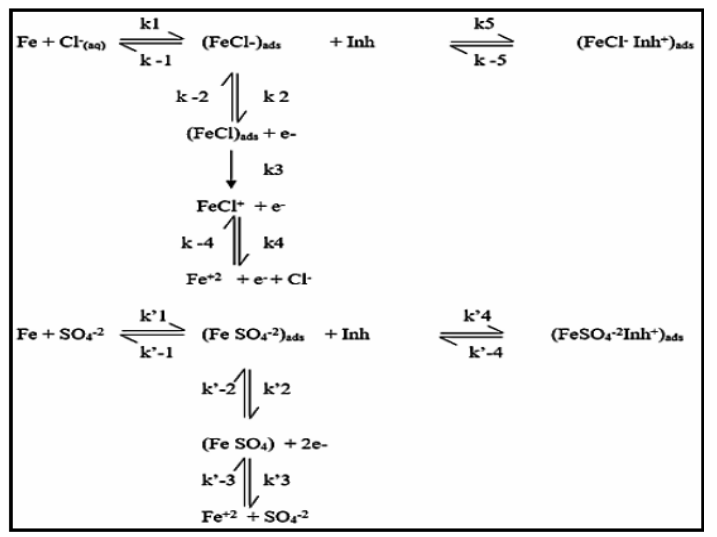

Fig. 7. Adsorption of anions and protonated BPS onto MS surface in acid media

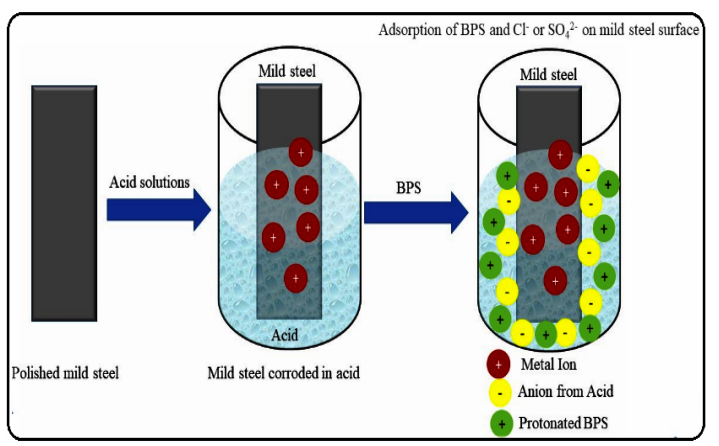

Fig. 8. Arrangement of ions in the system containing the inhibitor

Determination of Adsorption Behavior

Adsorption behavior of inhibitor molecules on MS surface has been deduced in terms of the adsorption isotherms. Generally, adsorption is considered as substitution surface phenomena in which organic molecules replace water molecules adsorbed on a metal surface and the process is described in previous literature ${ }^{33}$. The mechanism for the BPS adsorption on the meal surface can be described based on the surface coverage and corrosion inhibition efficiency of BPS. In the present study, different types of adsorption isotherms were tested to match experimental data, including Freundlich, Temkin and Langmuir and it was found that the experimental data matched well with Langmuir model, which can be stated as

$\mathrm{C}_{\text {inh }} / \theta=\mathrm{C}_{\mathrm{inh}}+1 / \mathrm{K}_{\mathrm{ads}}$

Here, $\mathrm{C}_{\text {inh }}$ indicates the concentration of the BPS, $\theta$ represents MS surface is covered by BPS. and $\mathrm{K}_{\mathrm{ads}}$ indicates the adsorption equilibrium constant. Plots of $C_{i n h}$ against $C_{i n h} / \theta$ yield straight lines as illustrated in Fig. 9a \& 9b. From these straight lines, the values of slope, intercepts and linear correlation coefficient $\left(R^{2}\right)$ obtained. It is evident that both slope and $R^{2}$ values are nearly equal to 0.99 , showing that BPS adsorption on mild steel surface follows Langmuir model in the acid media. The values of $\mathrm{K}_{\text {ads }}$ were determined from the intercept of the straight lines and it is used to compute the value of the standard free energy of adsorption $\left(\Delta G_{\text {ads }}\right)$ using the following expression 27,34 .
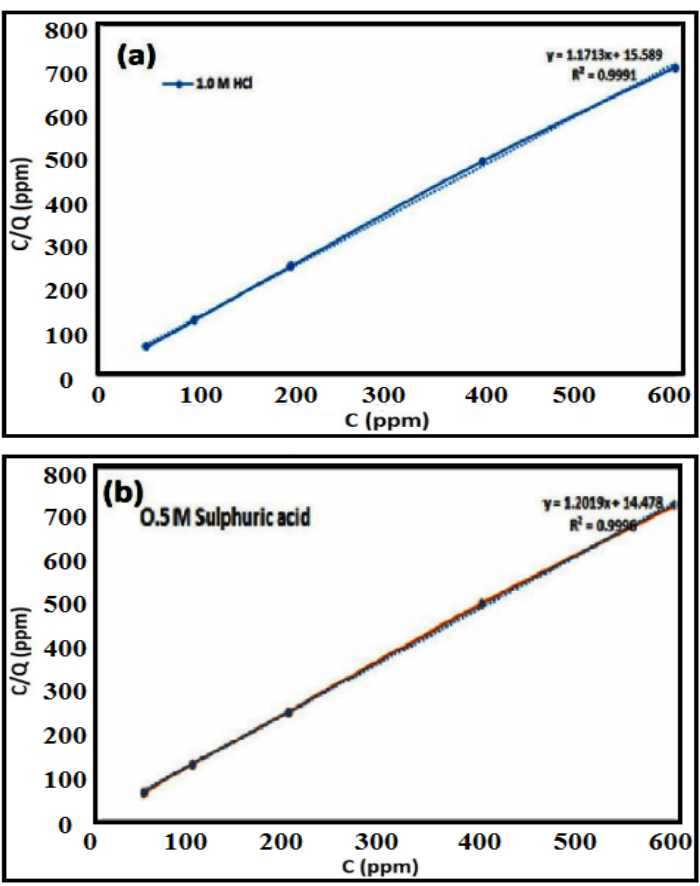

Fig. 9. The ratio of $C$ to $\theta$ against $C$ against for MS $\mathrm{K}_{\mathrm{ads}}=1 / 55.5 \exp \left(\Delta \mathrm{G}_{\mathrm{ads}} / \mathrm{RT}\right)$

Here, $\mathrm{T}$ is the thermodynamic temperature, $\mathrm{R}$ denotes gas constant and 55.5 denotes the molar concentration of $\mathrm{H}_{2} \mathrm{O}$. In general, the inhibitor molecules are said to be adsorbed by physisorption mechanism if the value of $\Delta \mathrm{G}_{\mathrm{ads}}$ less than $20 \mathrm{~kJ} / \mathrm{mol}^{132}$.

If the value of $\Delta G_{\text {ads }}$ is greater than $40 \mathrm{~kJ} / \mathrm{mol}$, it indicates that inhibitors are primarily adsorbed to the mild steel surface through chemical adsorption ${ }^{32}$. On the other hand, if this value is in between $20 \mathrm{kJmol}^{-1}$ and $40 \mathrm{kJmol}^{-1}$, then it indicates the adsorption of inhibitor on the tested metal surface involves mixed type of adsorption ${ }^{30,32}$. The negative sign of $\Delta G_{\text {ads }}$ clearly shown that adsorption of BPS on MS surface occurs spontaneously. As a result of this work, the estimated $\Delta G_{\text {ads }}$ values are ranged from $-46.82 \mathrm{~kJ} / \mathrm{mol}$ and $-44.14 \mathrm{~kJ} / \mathrm{mol}$ which is larger than $40 \mathrm{~kJ} / \mathrm{mol}$. This 
suggests that co-ordinate adsorption is involved in the adsorption of BPS on mild steel in corrodents ${ }^{27,32}$.

\section{Effect of Temperature}

Nyquist plots were recorded for mild steel in the temperature range, 303 to $323 \mathrm{~K}$ in the absence and presence of BPS (at $600 \mathrm{ppm}$ ), which are shown in Fig.10a to 10d. The Arrhenius type of plots obtained by plotting $\log \left(1 / \mathrm{R}_{\mathrm{ct}}\right)$ against $1 /$ Temperature in both the acid media in the absence and presence of the synthesized BPS are displayed in Fig.11a and 11b. The energy of activation values obtained from

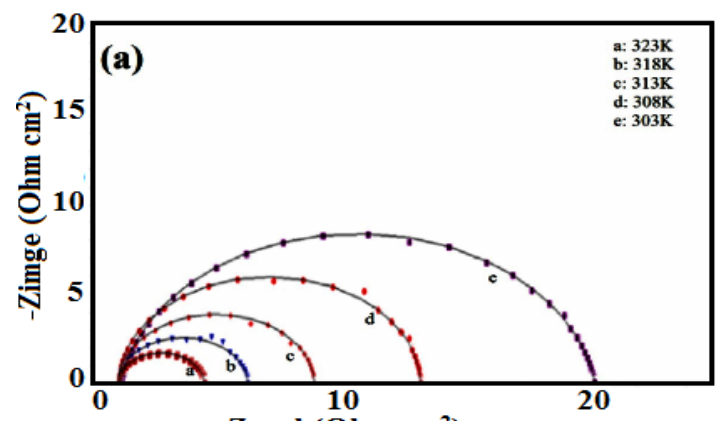

Zreal $\left(\mathrm{Ohm} \mathrm{cm}^{2}\right)$

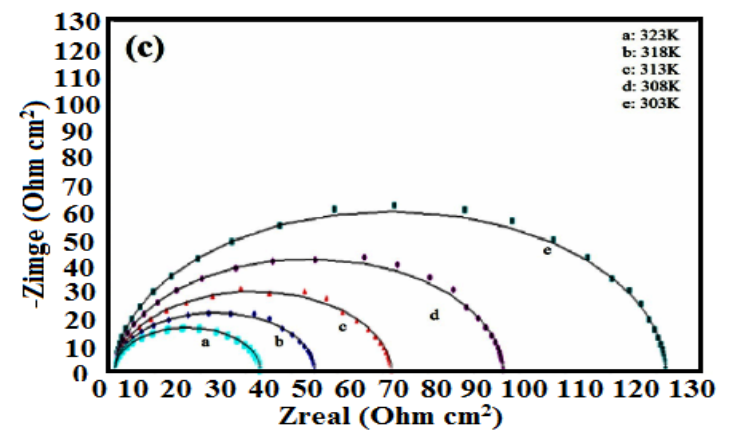

Fig. 10. EIS plots of MS in (a) $1.0 \mathrm{M} \mathrm{HCl}$ at various temperature (b) $0.5 \mathrm{MH}_{2} \mathrm{SO}_{4}$ at various temperature (c) $1.0 \mathrm{M} \mathrm{HCl}$ with $600 \mathrm{ppm}$ of BPS at various temperature and d) $0.5 \mathrm{MH}_{2} \mathrm{SO}_{4}$ with $600 \mathrm{ppm}$ of $\mathrm{BPS}$ at various temperature

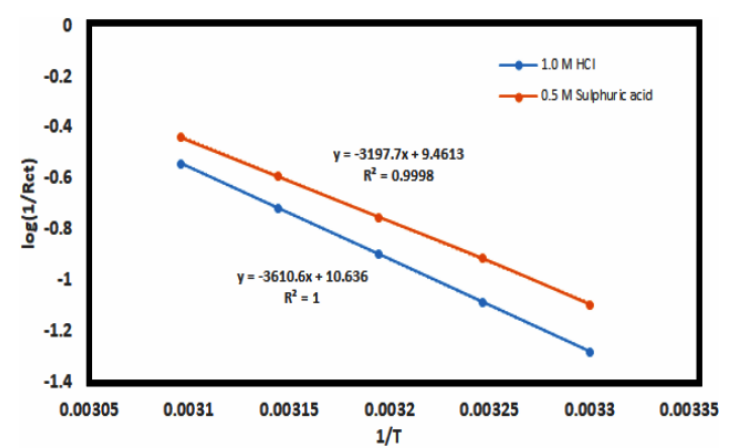

Fig.11a. A typical plot of log (1/ Rct) versus $1 / T$ for MS in tested corrodents

These plots explain the effect of addition of corrosion inhibitor molecules on the energy of activation for the corrosion of MS in acid media. In the Arrhenius plots ${ }^{27}$ are presented in Table 4.

$\log \left(1 / R_{c t}\right) a \log ($ corrosion rate $)=-E_{a} / 2.303 R(1 / T)+$ $\log A$

Table 4: Energy of activation for the MS in corrodents in the absence and presence of BPS.

\begin{tabular}{ccc}
\hline S.No. & Medium & $\begin{array}{c}\text { Energy of activation } \\
(\mathrm{kJ} / \mathrm{mol})\end{array}$ \\
\hline 1 & $\mathrm{HCl}(1.0 \mathrm{M})$ & 69.13 \\
2 & $\mathrm{H}_{2} \mathrm{SO}_{4}(0.5 \mathrm{M})$ & 61.23 \\
3 & $\mathrm{HCl}(1 \mathrm{M})+\mathrm{BPS}(600 \mathrm{ppm})$ & 54.19 \\
4 & $\mathrm{H}_{2} \mathrm{SO}_{4}(0.5 \mathrm{M})+\mathrm{BPS}(600 \mathrm{ppm})$ & 50.78 \\
\hline
\end{tabular}
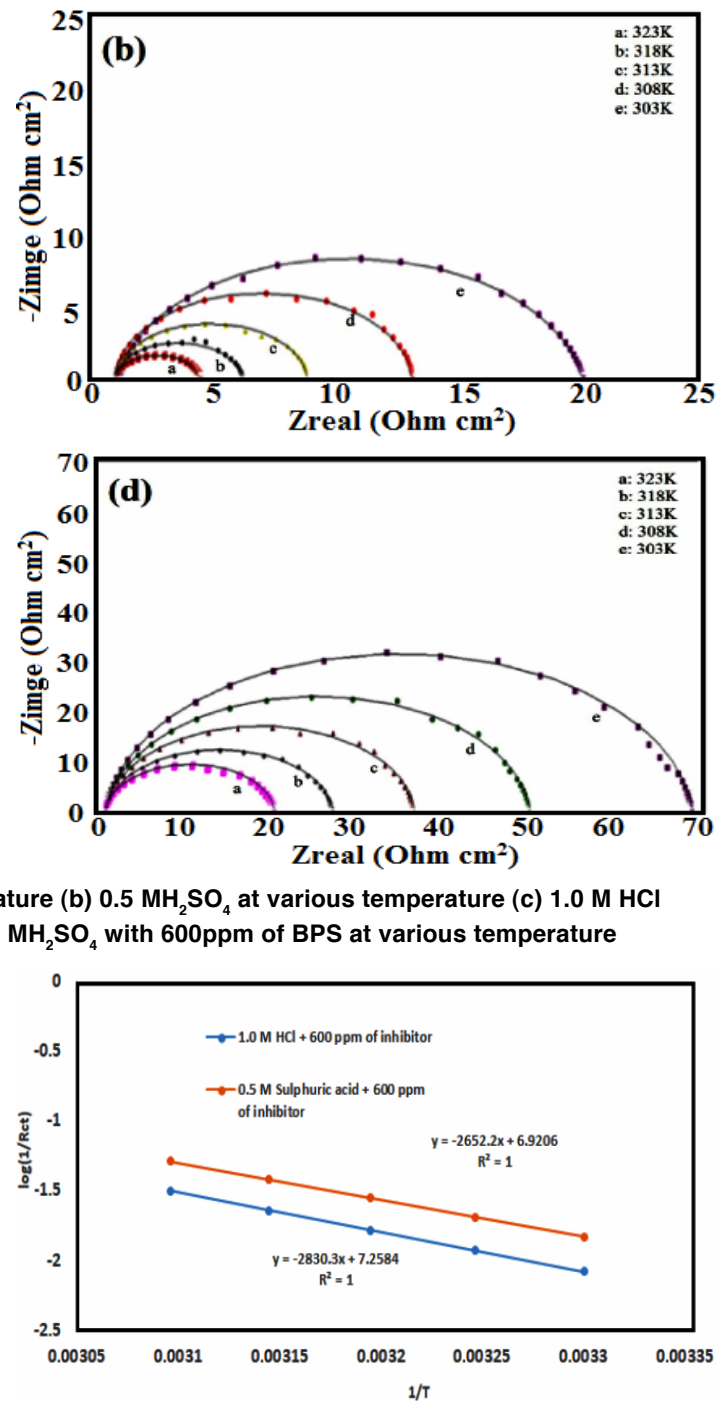

Fig. 11b. A typical plot of $\log \left(1 / R_{c t}\right)$ versus $1 / T$ for $M S$ in tested corrodents containing 600ppm of BPS

the present study we observed that the energy of activation diminishes due to adsorption of BPS on tested material surface that reduces the uncovered 
area of specimens comes in contact with corrosive media, showing decreased rate of corrosion and interpreted as chemisorption ${ }^{30}$. In the literature, the diminish in activation energy in an aggressive environment caused by inhibitor molecules was clarified in various ways ${ }^{35-38}$. It is well known that an increase in temperature will influence the kinetics adsorption of inhibitor onto steel specimens' surface and also adsorption equilibria ${ }^{33}$. The adsorption of BPS molecules on the surface area of mild steel increases as the temperature rises, resulting the creating of insulating film that inhibits dissolution of mild steel in corrosive medium ${ }^{39}$. According to Mistry et al., adsorption of inhibitor to the surface of mild steel, where they have substantial impact in the overall rate of metal dissolution ${ }^{30}$. The corrosion of metal surface could be less in the current study due to the high degree of surface coverage. This led to conclude that at high degree of surface coverage the interaction is between the electrode surface and BPS molecules. In this situation, the energy of activation can be lower or greater than when BPS molecules are present ${ }^{40}$.

According to other authors ${ }^{41-44}$, chemisorption is the cause of the decreased activation energy in the presence of inhibitor. The $R_{c t}$ values obtained from the
Nyquist plots are shown in Table 5 and 6 . Table 7 shows the \%IE for different organic compounds employed as inhibitors in acid media. BPS could serve as efficient inhibitors, based on evidence from various organic compounds and our data.

Table 5: Effect of thermodynamic temperature on MS corrosion in both corrodent in the absence of BPS

\begin{tabular}{lccc}
\hline S. No. & Temperature (K) & \multicolumn{2}{c}{$\begin{array}{c}\text { Charge transfer resistance } \\
(\text { Ohm cm²) }\end{array}$} \\
& & $\mathrm{HCl}(1 \mathrm{M})$ & $\mathrm{H}_{2} \mathrm{SO}_{4}(0.5 \mathrm{M})$ \\
\hline 1 & 303 & 19.1 & 12.5 \\
2 & 308 & 12.2 & 8.23 \\
3 & 313 & 7.92 & 5.66 \\
4 & 318 & 5.23 & 3.93 \\
5 & 323 & 3.49 & 2.76 \\
\hline
\end{tabular}

Table 6: Effect of thermodynamic temperature on MS corrosion in both corrodent in the presence of BPS

\begin{tabular}{lccc}
\hline S.No. & Temperature $(\mathrm{K})$ & \multicolumn{2}{c}{$\begin{array}{c}\text { Charge transfer resistance } \\
\left.(\mathrm{Ohm} \mathrm{cm})^{2}\right)\end{array}$} \\
& & $\begin{array}{c}\mathrm{HCl}+600 \mathrm{ppm} \\
\mathrm{BPS}\end{array}$ & $\begin{array}{c}\mathrm{H}_{2} \mathrm{SO}_{4}+600 \mathrm{ppm} \\
\text { inhibitor }\end{array}$ \\
\hline 1 & 303 & 120.9 & 67.9 \\
2 & 308 & 85.3 & 49.1 \\
3 & 313 & 60.8 & 35.7 \\
4 & 318 & 43.9 & 26.3 \\
5 & 323 & 31.9 & 19.5 \\
\hline
\end{tabular}

Table 7: Protection efficiency of various organic compounds on mild steel in various corrodent

\begin{tabular}{|c|c|c|c|c|c|c|}
\hline \multirow[t]{2}{*}{ Organic inhibitor } & \multirow[t]{2}{*}{ Metal exposed } & \multirow[t]{2}{*}{ Test solution } & \multicolumn{3}{|c|}{ Measurements (\%IE) } & \multirow[t]{2}{*}{ Ref } \\
\hline & & & Weight loss & Tafel & Impedance & \\
\hline 4-amino antipyridine & MS & $\mathrm{HCl}$ & 72.6 & 82.8 & 55.7 & {$[45]$} \\
\hline Diethyl pyrazine-2-3, carboxylate & MS & $\mathrm{H}_{2} \mathrm{SO}_{4}$ & 82 & 80 & 80 & {$[46]$} \\
\hline $\begin{array}{l}\text { N1- furan- 2-yl-methylene hydrazine } \\
\text { carbodithioic acid }\end{array}$ & MS & $\mathrm{HCl}$ & 85 & 91.65 & 80.3 & {$[47]$} \\
\hline $\begin{array}{l}\text { N1-(3-nitro-benzylidene)hydrazine } \\
\text { carbodithioic acid }\end{array}$ & MS & $\mathrm{HCl}$ & 80 & 87.8 & 80.5 & {$[48]$} \\
\hline Pyrazole & MS & $\mathrm{HCl}$ & - & 70.34 & 61.63 & {$[49]$} \\
\hline \multirow[t]{2}{*}{ BPS } & MS & $\mathrm{HCl}$ & 84.5 & 83.5 & 84.2 & In this work \\
\hline & & $\mathrm{H}_{2} \mathrm{SO}_{4}$ & 82.2 & 81.2 & 81.6 & \\
\hline
\end{tabular}

\section{SEM Analysis}

SEM images of mild steel specimens soaked

in the tested solutions for $2 \mathrm{~h}$ with and without BPS are presented in Fig. 12. From the scanning electron micrographs, it is obvious that in the absence of BPS cracks are formed on the metal surface due to severe acid attack. In the presence of BPS in the acid medium, the mild steel surface cracks are significantly decreased due to the deposition of BPS molecules on the tested metal surface.

\section{Determination of Surface roughness}

Atomic force microscopy (AFM) is used to investigate the effect inhibitor on materials microstructure. The generation and progress of corrosion in the presence and absence of BPS can be monitored using $A F M^{50-53}$. The three-dimensional and cross-sectional AFM microstructure of MS specimens soaked in the inhibited and uninhibited acid solutions are shown in Fig.13 and 14. It is observed from figures that the peak-to valley value 
decreases with the addition of inhibitor suggesting the good coverage on metal surface by the synthesized Schiff base molecules in acid media.

\section{Antimicrobial studies}

The zones of inhibition of synthesized Schiff base for the antimicrobial studies are presented in Table 8 and 9. From these tables, it is clearly seen that the zone of inhibition increase with the amount of BPS and we found that when the amount of Schiff base is $100 \mathrm{mcg}$ the Zone of inhibition is maximum. It is also seen that the synthesized Schiff base inhibits the growth of Gram-negative bacteria and the fungi $A$. niger and $C$. albicans than the Gram-positive bacteria.
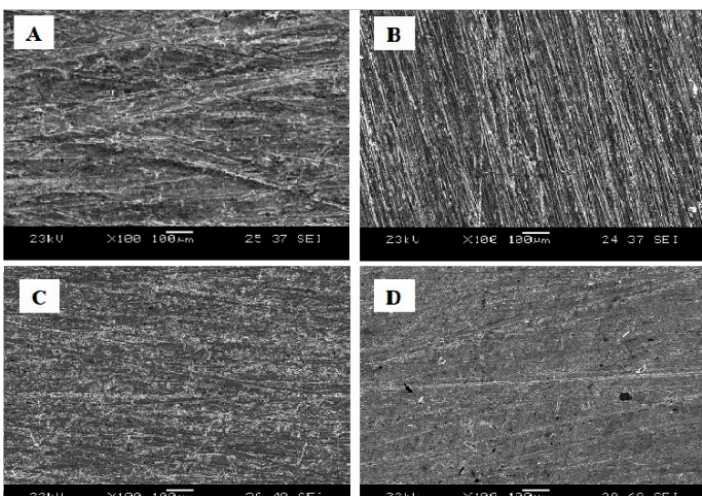

Fig. 12. SEM of mild steel (a) $0.5 \mathrm{M} \mathrm{H}_{2} \mathrm{SO}_{4}$ (b) $1 \mathrm{M} \mathrm{HCl}$ (c) treated with $600 \mathrm{ppm}$ of BPS (d) treated with $600 \mathrm{ppm}$ of BPS
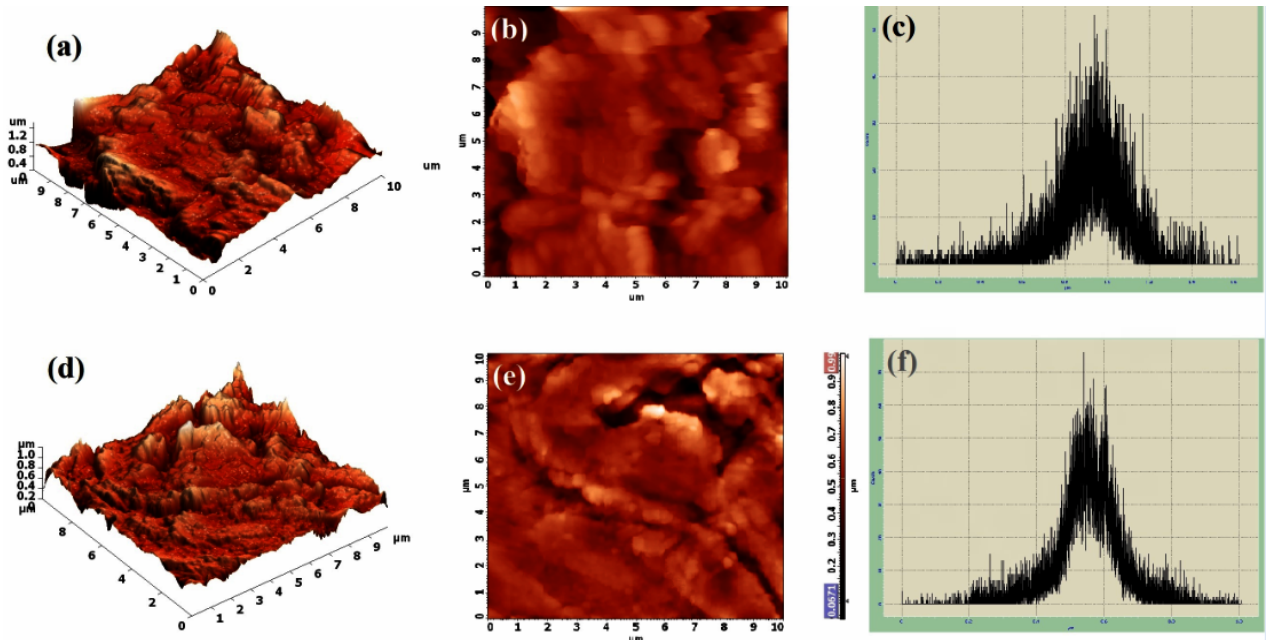

Fig. 13. AFM of MS (a) corroded in $1 \mathrm{M} \mathrm{HCl}$ (Three-dimensional view) (b) corroded in $1 \mathrm{M} \mathrm{HCl}$ (Two dimensional cross-sectional view) (c) Cross sectional profiles of $\mathrm{MS}$ in $1 \mathrm{M} \mathrm{HCl}$ (d) treated with $600 \mathrm{ppm}$ of BPS (Three-dimensionl view) (e) treated with $600 \mathrm{ppm}$ of BPS (Two dimensional cross-sectional view). (f) Cross sectional profiles of MS in $1 \mathrm{M} \mathrm{HCl} \mathrm{containing} \mathrm{600ppm} \mathrm{of} \mathrm{BPS}$
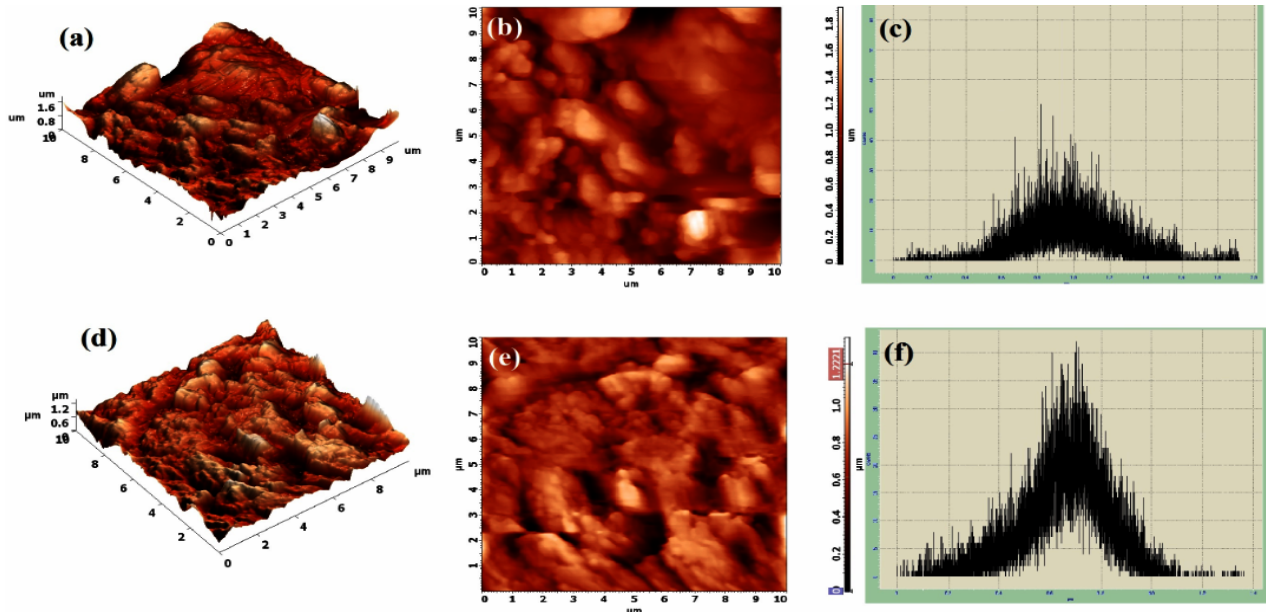

Fig. 14. AFM of MS (a) corroded in $0.5 \mathrm{M} \mathrm{H}_{2} \mathrm{SO}_{4}$ (Three-dimensional view) (b) corroded in $0.5 \mathrm{M} \mathrm{H}_{2} \mathrm{SO}_{4}$ (Two dimensional cross-sectional view) (c) Cross sectional profiles of $\mathrm{MS}$ in $0.5 \mathrm{M} \mathrm{H}_{2} \mathrm{SO}_{4}$ (d) treated with 600ppm of BPS (Three-dimensional view) (e) treated with 600ppm of BPS (Two dimensional cross-sectional view). (f) Cross sectional profiles of MS in $0.5 \mathrm{M}$ $\mathrm{H}_{2} \mathrm{SO}_{4}$ containing $600 \mathrm{ppm}$ of BPS 
Table 8: Zone of inhibition of synthesized BPS

\begin{tabular}{|c|c|c|c|c|c|c|c|c|c|c|c|c|c|c|c|c|}
\hline \multirow[t]{4}{*}{ Compound code } & \multicolumn{16}{|c|}{ Antibacterial activity } \\
\hline & \multicolumn{9}{|c|}{ Gram-positive } & \multicolumn{7}{|c|}{ Gram-negative } \\
\hline & \multicolumn{4}{|c|}{ Staphylococcus aureus } & \multicolumn{4}{|c|}{ Bacillus saptilus } & & \multicolumn{4}{|c|}{ Salmonella typhi } & \multicolumn{3}{|c|}{ E. coli } \\
\hline & 100 & 50 & 25 & Std & 100 & 50 & 25 & Std & 100 & 50 & 25 & Std & 100 & 50 & 25 & Std \\
\hline BPS & 14 & 10 & 6 & 17 & 11 & 9 & 6 & 26 & 12 & 9 & 6 & 25 & 15 & 11 & 7 & 26 \\
\hline
\end{tabular}

Table 9: Zone of inhibition of synthesized BPS

\begin{tabular}{|c|c|c|c|c|c|c|c|c|}
\hline \multirow[t]{3}{*}{ Compound code } & \multicolumn{8}{|c|}{ Antifungal activity } \\
\hline & \multicolumn{4}{|c|}{ A. niger } & \multicolumn{4}{|c|}{ C. albicans } \\
\hline & $100 \mathrm{mcg}$ & $50 \mathrm{mcg}$ & $25 \mathrm{mcg}$ & Std & $100 \mathrm{mcg}$ & $50 \mathrm{mcg}$ & $25 \mathrm{mcg}$ & Std \\
\hline BPS & 14 & 9 & 7 & 26 & 13 & 5 & - & 18 \\
\hline
\end{tabular}

\section{CONCLUSION}

The following are the findings of the current research. The protection efficiency of the synthesized BPS enhanced with raise in the BPS concentration in $1 \mathrm{M} \mathrm{HCl} \& 0.5 \mathrm{M} \mathrm{H}_{2} \mathrm{SO}_{4}$ solutions. The highest protection efficiency $(82.2 \%$ in 0.5 $\mathrm{M} \mathrm{H}_{2} \mathrm{SO}_{4}$ and $84.5 \%$ in $1.0 \mathrm{M} \mathrm{HCl}$ ) was noticed at $600 \mathrm{ppm}$. The results of weight loss data are supported by electrochemical studies. The $R_{c t}$ of BPS increases linearly with increasing BPS concentration, according to EIS measurements. The results from Tafel polarization confirmed that the tested BPS is mixed type. The $\Delta G_{\text {ads }}$ calculated from adsorption isotherm shows that the BPS adsorbed on the MS surface in acid media is spontaneous and adsorption involves chemisorption's mechanism.
PZC studies indicated the adsorption of prorogated BPS molecules onto the MS surface involves physisorption through the anion bridges. The synthesized Schiff base has shown and appreciable antimicrobial activity at $100 \mathrm{mcg}$. It inhibits better the growth of Gram-negative bacteria and fungi than Gram-positive bacteria.

\section{ACKNOWLEDGMENT}

This research did not receive any specific grant from funding agencies in the public, commercial, or not-for-profit sectors.

\section{Conflict of interest}

The author declare that we have no conflict of interest.

\section{REFERENCES}

1. Prabhu, R. A.; Venkatesha, T. V.; Shanbhag, A.V.; Praveen, B.M.; Kulkarni, G. M.; Kalkhambkar, R.G. Mater. Chem. Phys. 2008, 108, 283-289.

2. Ahamad, I.; Prasad, R.; Quraishi, M.A. Corros. Sci., 2010, 52, 933-942.

3. Shaban, S.; Elmorsi, M.; Fayed, T.; Azazy, O. Anti-Corrosion Methods and Materials., 2018, 65, 197-209.

4. Raja, P.B.; Ismail, M.; Ghoreishiamiri, S.; Mirza, J.; Ismail, M.C.; Kakooei, S.; Rahim, A.A. Chem. Eng. Commun., 2016, 203, 1145-1156.

5. Saha, S.K.; Hens A.; RoyChowdhury A.; Lohar A.K.; Murmu N.C.; Banerjee, P. Can Chem Trans., 2014, 2, 489-503.

6. Ahamad, I.; Prasad R.; Quraishi, M.A. Corros. Sci., 2010, 52, 3033-3041.

7. Bentiss, F.; Traisnel, M.; Lagrenee, M. Corros.
Sci., 2000, 42, 127-146.

8. Morad, M.S. Corros. Sci., 2008, 50, 436-48.

9. Musa, A.Y.; H.; Kadhum, A.A.H.; Mohamad, A.B.; Takriff, M.S.; Daud, A.R.; Kamarudin, S.K. Corros. Sci., 2010, 52, 526-533.

10. Hasanov, R.; Sadıkoğlu, M.; Bilgiç, S. Appl. Surf. Sci., 2007, 253, 3913-3921.

11. Hefter, G.T.; North, N.A.; Tan, S.H. Corrosion., 1997, 53, 657-667.

12. Ju, H.; Kai, Z.P.; Li, Y. Corros. Sci., 2008, 50, 865-871.

13. Yıldırım, A.; Cetin, M. Corros. Sci., 2008, 50, 155-165.

14. Fang J.; Li. J. J. Mol. Struct: Theochem., 2002, 593, 179-185.

15. Obot, I.B.; Obi-Egbedi, N.O. Corros. Sci., 2010, 52, 657-660.

16. Ahamad, I.; Prasad, R.; Quraishi, M.A; Corros. Sci., 2010, 52, 933-942. 
17. Gonczy, S.T.; Randall, N. Int. J. Appl. Ceram. Technol., 2005, 5, 422-428.

18. Yurt, A.Y.; Balaban, A., Kandemir, S.U.; Bereket G.; Erk B. Mater. Chem. Phys., 2004, 85, 420-426.

19. Wang, H.L.; Liu, R.B.; Xin J. Corros. Sci., 2004, 46, 2455-2466

20. Herrag, L.; Hammouti, B.; Elkadiri, S.; Aouniti, A.; Jama, C.; Vezin, H.; Bentiss, F. Corros. Sci., 2010, 52, 3042-3051.

21. Ahamad, I.; Prasad, R., Quraishi, M.A. J Solid State Electrochem., 2010, 14, 2095-2105.

22. Ahamad, I.; Gupta, C.; Prasad, R.; Quraishi, M. A. J. Appl. Electrochem., 2010, 40, 2171-2183.

23. Hao, Y.; Sani, L.A.; Ge T.; Fang Q. Corros. Sci., 2017, 123, 158-169.

24. Mallaiya, K.; Subramaniam, R.; Srikandan, S.S.; Gowri, S.; Rajasekaran, N.; Selvaraj, A. Electrochim. Acta., 2011, 56, 3857-3863.

25. Shukla, S.K.; Quraishi, M.A. Corros. Sci., 2009, 51, 1007-1011.

26. Ahamad, I.; Quraishi, M.A. Corros. Sci., 2010, 52, 651-656.

27. Ebenso, E.E.; Ekpe, U.J.; Ita, B.I.; Offiong, O.E.; Ibok, U. J. Mater. Chem. Phys., 1999, 60, 79-90.

28. Limo, M.J.; Sola-Rabada, A.; Boix, E.; Thota, V.; Westcott, Z.C.; Puddu, V.; Perry C.C. Chem Rev., 2018, 118, 11118-11193.

29. Al-Amiery A.A.; Kassim F.A.; Kadhum A.A.; Mohamad, A.B. Sci.Rep., 2016, 6, 1-3.

30. Mistry, B.M.; Kim D.H.; Jauhari, S. Trans. Indian Inst. Met., 2016, 69, 1297-1309.

31. Nithya, P.; Rameshkumar, S.; Sankar, A. Int. J. Eng. Sci., 2016, 5, 66-74

32. Singh A.; Ansari, K.R.; Kumar, A.; Liu W.; Songsong C.; Lin Y. J Alloy Compd., 2017, 712, 121-133.

33. Li. W.; He. Q.; Pei. C.; Hou, B. Electrochim Acta., 2007, 52, 6386-6394.

34. Kharacha, S.; Batah, A.; Belkhaouda, M.; Bazzi, L.; Bammou, L.; Salghi, R.; Jbara, O.;
Tara A. Mor. J. Chem., 2018, 6, 6-2.

35. De Souza, F.S.; Spinelli, A. Corros. Sci., 2009, 51, 642-649.

36. Popova, A.; Sokolova, E.; Raicheva, S.; Christov M. Corros. Sci., 2003, 45, 33-58.

37. Bouyanzer, A.; Hammouti, B.; Majidi, L. Mater. Lett. 2006, 60, 2840-2843.

38. Garai, S.; Garai, S.; Jaisankar, P.; Singh, J.K.; Elango, A. Corros. Sci., 2012, 60, 193-204.

39. Solmaz, R.; Kardaş, G.Ü; Culha, M.; Yazıcı, B.; Erbil, M.E. Electrochim Acta., 2008, 53, 5941-5952.

40. Avci, G. Colloids Surf A. Physicochem. Eng. Asp., 2008, 317, 730-736.

41. Olasunkanmi, L.O.; Obot, I.B.; Kabanda, M.M.; Ebenso, E. E. J. Phys. Chem. C., 2015, 119, 16004-16019.

42. Finšgar, M. Corros. Sci., 2013, 72, 90-98.

43. Tao, Z.; He, W.; Wang, S.; Zhang, S.; Zhou, G. Corros. Sci., 2012, 60, 205-213.

44. Mobin, M.; Basik, M.; Shoeb, M. Appl. Surf. Sci., 2019, 469, 387-403.

45. Abd El-Rehim,S. S.; Ibrahim,M. A. M.; Khaled, K. F. J. Appl. Electrochem., 1999, 29, 593-599

46. Bouklah,M.; Attayibat,A.; Kertit,S.; Ramdani,A.; Hammouti, B. Appl. Surf. Sci., 2005, 242, 399-406.

47. Hosseini,S.M.A.; Azimi, A. Corros. Sci., 2009, 51, 728-732.

48. Khaled, K.F. Appl. Surf. Sci., 2006, 252, 41204128.

49. Abdel-Rehim,S.S.; Khaled,K.F.; Al-Mobarak, N.A. Arabian J.Chem., 2011, 4, 333-337.

50. Singh, D.K.; Kumar, S.; Udayabhanu, G.; John, R.P. J. Mol. Liq., 2016, 216, 738-46.

51. Verma, C.; Quraishi, M.A.; Ebenso, E.E.; Obot, I.B.; El Assyry, A. J. Mol. Liq., 2016, 219, 647-660.

52. Keramatinia, M.; Ramezanzadeh, B.; Mahdavian, M. J. Taiwan Inst Chem E., 2019, 105, 134-149.

53. Zhang, F.; Pan, J.; Claesson, P.M. Electrochim Acta., 2011, 56, 1636-1645. 